\title{
EMPREENDEDORISMO TECNOLÓGICO COMO OPÇÃO CARREIRA NA APOSENTADORIA
}

\begin{abstract}
José Roberto Souza Freire - Universidade Municipal de São Caetano do Sul ${ }^{1}$ Isabel Cristina dos Santos - Universidade Municipal de São Caetano do Sul ${ }^{2}$ Silvio Aparecido dos Santos - Faculdade de Administração e Economia - FEA/USP ${ }^{3}$ Adriana Domingos M. de Castro - Universidade Municipal de São Caetano do Sul ${ }^{4}$ Darticléia Almeida Sampaio da Rocha Soares - Universidade Municipal de São Caetano do Sul
\end{abstract}

Resumo: Institutos de Ciência e Tecnologia são organizações que constroem grandes acervos de conhecimento de ponta, combinando conhecimento explícito e tácito decorrente da formação do pesquisador. Há potencial para que o empregado em fase de aposentadoria defina um novo curso de carreira, com foco na aplicação dos saberes de alto valor agregado que acumularam durante a carreira. Nesse sentido, o presente artigo se insere nesta categoria e busca descrever as estratégias oriundas dessas instituições como uma oportunidade do empreendedorismo como opção de segunda carreira para os empregados que estão se aposentando e saindo da instituição. Trata-se de uma pesquisa de natureza quantitativa e do tipo exploratória. Tem por finalidade, contribuir na política de recursos humanos, estimulando os programas de intraempreendedorismo e preparando os pesquisadores para o empreendedorismo tecnológico como uma opção de segunda carreira. Os resultados confirmam o empreendedorismo tecnológico como uma opção desejada pelos pesquisadores como encaminhamento pós-aposentadoria. Conclui-se que, para as instituições de pesquisa, essa opção é uma estratégia adequada para a transferência gradual de conhecimento.

Palavras-chave: Empreendedorismo de Base Tecnológica; Transferência de Tecnologia; Aposentadoria; Qualidade de Vida.

\section{TECHNOLOGICAL ENTREPRENEURSHIP AS A CAREER OPTION IN RETIREMENT}

Abstract: Institutes of Science and Technology are capable of generating large collections of knowledge, combining explicit and tacit knowledge that arise from researcher formation. It brings up an opportunity of new career for those employees in retiring process, and gives them a chance to keep contributing and adding value through the technological knowledge they have accumulated in their professional lifetime. Therefore, this article seeks to describe the strategies from such institutions to create entrepreneurship opportunities as an option of second career for employees who are retiring and leaving the institution. It is a quantitative

\footnotetext{
${ }^{1}$ E.mail: joserobertofreire@gmail.com - Endereço: Rua Santo Antônio, 50, Centro, São Caetano do Sul - SP, CEP: 09521-160.

${ }^{2}$ E.mail: isa.santos.sjc@gmail.com

3 E.mail: sadsanto@usp.br

${ }^{4}$ E.mail: adriana.castro1999@hotmail.com

${ }^{5}$ E.mail: dartisoares@terra.com.br
}

DOI: 10.14211regepe3281. FREIRE, J. R. S.; SANTOS, I. C.; SANTOS, S. A.; CASTRO, A. D. M.; SOARES, D. A. S. R. Empreendedorismo tecnológico como opção de segunda carreira: pós-aposentadoria. Revista de Empreendedorismo e Gestão de Pequenas Empresas, v. 3, n. 2, p. 94-119, 2014. 
and exploratory research, and aims to contribute in human resources development policies, encouraging entrepreneurship programs and preparing employees for technological entrepreneurship as an option of second career. The results pointed out that technological entrepreneurship as a desirable choice for researchers on retiring process. So, to the research institutions, can conclude that is a valid strategy for a gradual transfer of knowledge.

Keywords: Entrepreneurship of Technological Base; Technology Transfer; Retirement; Quality of Life.

\section{Introdução}

Antes de tudo, é preciso dizer que as Instituições de Pesquisa, Desenvolvimento e Inovação (PD\&I) são classificadas como organizações intensivas em conhecimento. Por sua natureza associada à pesquisa aplicada, essas instituições empregam em suas áreas operacionais, profissionais altamente qualificados, com grande capacidade de aprendizado e de conversão de conhecimento em soluções tecnológicas que atendam as expectativas dos clientes.

Em princípio, a partir de sua qualificação, os empregados são capazes de criar novos conhecimentos, definir novos protocolos de pesquisa e disseminar novos conhecimentos. Esses profissionais contribuem diretamente para a construção da imagem e reputação da instituição. São ainda responsáveis pela captação de recursos junto aos órgãos de fomento e, indiretamente, pela atualização dos recursos tecnológicos e materiais utilizados na pesquisa. A soma de suas competências em solução tecnológica torna-se um atrativo na geração de receitas financeiras para a instituição que, por sua vez, para manter o conhecimento no estado da arte, investe de forma contínua e estratégica na qualificação e capacitação profissional. Como consequência da capacitação, esses profissionais são disputados no mercado.

Outra consequência da qualificação dos empregados é que o conhecimento acumulado por eles é fator potencial na criação de empreendimentos de base tecnológica. Os projetos de pesquisas desenvolvidos dentro dessas instituições têm por finalidade a geração de novas tecnologias e o processo de acumulação de conhecimento, que envolve o conhecimento explícito e o tácito, sendo responsáveis pela formação de competência para soluções tecnológicas. Assim, esses

DOI: 10.14211regepe3281. FREIRE, J. R. S.; SANTOS, I. C.; SANTOS, S. A.; CASTRO, A. D. M.; SOARES, D. A. S. R. Empreendedorismo tecnológico como opção de segunda carreira: pós-aposentadoria. Revista de Empreendedorismo e Gestão de Pequenas 
profissionais reúnem condições técnicas de criação de novos empreendimentos de base tecnológica (PEREIRA; BERA, 2009).

A criação de empresas de base tecnológica é uma forma de transferência de tecnologia especialmente vantajosa para o país e para a localidade, uma vez que além das vantagens econômicas, preserva o patrimônio científico nacional, oferecendo uma cultura empreendedora no interior das instituições numa associação com o mundo dos negócios. Por essa razão, o tema e o fenômeno de transbordamento de conhecimento atrai particular atenção das instituições de pesquisa e extensão e, principalmente, das instituições governamentais.

Nesse sentido, o desafio para as Instituições de Pesquisa é desenvolver um conjunto de estratégias para conseguir que seus ativos intangíveis, constituídos pelas competências advindas dos conhecimentos tácitos e explícitos dos relacionamentos e a da experiência dos seus especialistas, sejam empreendedores e continuem disponíveis à organização após suas aposentadorias. Se não houver uma ação estratégica nesta direção, a instituição corre o risco de perda contínua de memória organizacional, ainda que mantenha uma base de dados adequada ao suporte de novos projetos (MAGNANI, 2004; TAKEUCHI; NONAKA, 2008). A perda, neste caso, é da habilidade individual que caracteriza a forma particular de solucionar problemas, ou o conhecimento tácito, também chamado de "truques da profissão" (BORGES, 2001, TAKEUCHI; NONAKA, 2008).

Embora a aposentadoria soe como sinônimo de fim de carreira, o empregado se encontra em plena atividade intelectual quando chega esse momento. Além disso, segundo dados do Censo Demográfico de 2010 do Instituto Brasileiro de Geografia e Estatística - IBGE (2010b), a expectativa média de vida deve chegar aos 80 anos de idade em 2040. Isto significa que as pessoas estão vivendo mais e em plena capacidade laborativa. Internalizar o conceito empreendedor em empregados, sobretudo quando se encontram em processo de aposentadoria, constitui-se uma política de valorização na gestão de pessoas e uma estratégia de transferência de tecnologia e formação da cultura empreendedora na instituição.

Tendo isso em mente, o presente estudo tem como objetivo descrever e analisar a opinião dos aposentados e gestores das Instituições de Ciência e

DOI: 10.14211regepe3281. FREIRE, J. R. S.; SANTOS, I. C.; SANTOS, S. A.; CASTRO, A. D. M.; SOARES, D. A. S. R. Empreendedorismo tecnológico como opção de segunda carreira: pós-aposentadoria. Revista de Empreendedorismo e Gestão de Pequenas

Empresas, v. 3, n. 2, p. 94-119, 2014. 
Tecnologia acerca do empreendedorismo tecnológico como opção de carreira após a aposentadoria do profissional de pesquisa, destacando alguns fatores associados ao empreendedorismo que seriam desejáveis ao longo do processo de preparação para a aposentadoria.

A premissa que sustenta este trabalho é baseada na visão do pesquisador aposentado como sendo um potencial empreendedor, tendo a seu favor um grande acervo de conhecimento, vivências e experiências que constituem a competência tecnológica necessária para se estabelecer em um novo projeto de vida e trabalho.

\section{Revisão teórica}

Uma empresa de base tecnológica (EBT) surge do espírito empreendedor e reflete 0 transbordamento do conhecimento obtido ao longo das tecnologias desenvolvidas essencialmente dentro da organização da qual se origina. É uma empresa que nasce para explorar e capitalizar os resultados de pesquisa da ciência. A organização de origem pode ser uma universidade, um centro de pesquisa ou uma empresa privada. Normalmente, a empresa de base tecnológica possui mais de $50 \%$ das operações em pesquisa e desenvolvimento (P\&D), a maioria de seu pessoal é altamente qualificada e possui uma elevada densidade tecnológica (MENCK; OLIVEIRA FILHO, 2009).

As empresas de base tecnológica são consideradas de alta tecnologia. Côrtes et al. (2005) sugerem particularizar esse conceito àquelas empresas que dispõem de competência rara ou exclusiva em termos de produtos ou processos. A função de um empreendimento de base tecnológica é fornecer ao mercado soluções tecnológicas que contribuam para que seus clientes elevem sua performance técnica, mercadológica, produtiva e financeira.

O espírito empreendedor é traduzido pela disposição em assumir riscos, começar algo novo. O empreendedor é aquele que inicia, que detecta as oportunidades de negócios para realizar uma ideia ou projeto pessoal, inovando sempre. Assim, suas três características básicas são: necessidades de realização, disposição para assumir riscos e autoconfiança (DORNELAS, 2003, 2004).

DOI: 10.14211regepe3281. FREIRE, J. R. S.; SANTOS, I. C.; SANTOS, S. A.; CASTRO, A. D. M.; SOARES, D. A. S. R. Empreendedorismo tecnológico como opção de segunda carreira: pós-aposentadoria. Revista de Empreendedorismo e Gestão de Pequenas 
McClelland (1998), em seu estudo do comportamento humano, identificou três necessidades que justificam a motivação como uma pré-disposição intrínseca de ajustar o comportamento: poder, realização e afiliação. Embora tenham sido estudadas no ambiente corporativo comum, essas necessidades permitem compreender o comportamento do empreendedor. As necessidades de realização de metas e de obtenção de reconhecimento estão, muitas vezes, acima das necessidades financeiras. As pessoas com necessidade de realização evitam situações de baixo risco por entenderem que o sucesso facilmente atingido não se trata de uma realização verdadeira. Elas veem o resultado como uma oportunidade. Indivíduos assim são altamente motivados e empreendedores.

Nas EBTs, a inovação constitui um eixo central das estratégias e a presença de resultados expressivos de tecnologia de produto fundamenta o negócio central. Além dessas, outras características das EBTs estão apresentadas no Quadro 1 abaixo:

\begin{tabular}{|l|l|}
\hline 1 & Espírito empreendedor - transforma ideias em negócio. \\
\hline 2 & Capacidade inovativas em produtos, designs, serviços ou processos. \\
\hline 3 & Desenvolve produtos/serviços tecnologicamente novos ou melhorias significantes. \\
\hline 4 & Envolve membros das comunidades acadêmicas/pesquisadores. \\
\hline 5 & Geralmente emergem dentro das universidades ou Instituições de Pesquisa. \\
\hline 6 & $\begin{array}{l}\text { Grande componentes de P\&D - conhecimento intensivo, baseado na transferência da academia } \\
\text { à indústria. }\end{array}$ \\
\hline 7 & Ambiente de Network/Rede \\
\hline 8 & $\begin{array}{l}\text { A maior contribuição dessas empresas ao desenvolvimento tecnológico está no papel da } \\
\text { aquisição, transformação e disseminação de tecnologia já existente dentro de redes de inovação. }\end{array}$ \\
\hline 9 & Explora comercialmente uma inovação tecnológica que envolve elevado grau de incerteza. \\
\hline
\end{tabular}
QUADRO 1 - Características de EBT

Fonte: Adaptado de Filion (2000), Dornelas (2003, 2004) e Menck, Oliveira Filho (2009).

Essas características distinguem as EBTs daquelas empresas que se empenham intensamente em modernizar suas bases produtivas, modificando suas tecnologias de processo, mas cujas operações se concentram na produção de bens e serviços há muito existentes no mercado (CORTES et al., 2005). Considera-se, que a EBT seja aquela empresa intensiva em conhecimento e que incorpora a dimensão do esforço de constituição de capacidades tecnológicas na definição do seu negócio.

DOI: 10.14211regepe3281. FREIRE, J. R. S.; SANTOS, I. C.; SANTOS, S. A.; CASTRO, A. D. M.; SOARES, D. A. S. R. Empreendedorismo tecnológico como opção de segunda carreira: pós-aposentadoria. Revista de Empreendedorismo e Gestão de Pequenas Empresas, v. 3, n. 2, p. 94-119, 2014. 
Para Santos e Cunha (2004), uma das formas das universidades e Instituições de Pesquisa contribuírem para o desenvolvimento da sociedade é por meio da promoção de geração de empresas de base tecnológica por meio de spinoff. De acordo com alguns autores como Oliveira (2008), Roberts (1991) e Carayannis et al. (1998), há algumas categorias básicas de criação de EBT, conforme poder ser visualizado no Quadro 2 abaixo:

\begin{tabular}{|l|l|}
\hline Spin-off & $\begin{array}{l}\text { A empresa é criada a partir de uma tecnologia interna surge de uma universidade ou } \\
\text { instituição de P\&D pública ou privada e permanece administrada pelos geradores } \\
\text { (criadores/desenvolvedores). }\end{array}$ \\
\hline Spin-out & $\begin{array}{l}\text { A empresa é criada a partir de uma tecnologia interna, mas seu gerador não } \\
\text { permanece como majoritário e, portanto não exerce controle gerencial. }\end{array}$ \\
\hline Spin-in & $\begin{array}{l}\text { A empresa é criada externamente e a tecnologia gerada pela empresa mãe é } \\
\text { transferida integralmente. }\end{array}$ \\
\hline
\end{tabular}

QUADRO 2 - Categorias de Criação de Empresa de Bases Tecnológicas

Fonte: Adaptado de Roberts (1991), Caraynnis et al. (1998), Pérez e Sánchez (2003) e Santos e Cunha (2004).

Pesquisadores, gestores e colaboradores de um empreendimento de base tecnológica necessitam ter consciência dos desafios associados à geração de inovações e o mecanismo de transferência de tecnologia. Segundo Schumpeter (1982), a essência do empreendedorismo está na percepção e no aproveitamento das novas oportunidades no âmbito dos negócios ou na criação de novas formas do uso dos recursos. Este processo é chamado de "inovação".

Considerando que instituições intensivas em conhecimento, pelos investimentos contínuos em novos saberes e tecnologias, acabam criando grandes acervos de conhecimento, os profissionais de PD\&I, ao longo de suas carreiras, reúnem condições de optarem pelo empreendedorismo como opção da segunda carreira. Assim, neste estudo admite-se que a categoria de empresa de base tecnológica spin-off tem a característica necessária para a transferência de tecnologia aos empregados/servidores em processo de aposentadoria.

Para Pérez e Sánchez (2003), um empreendimento spin-off surge quando um empreendedor deixa uma organização para começar sua própria empresa. Além disso, é necessário que ocorra a transferência de alguns direitos de uma organização existente para essa nova empresa.

DOI: 10.14211regepe3281. FREIRE, J. R. S.; SANTOS, I. C.; SANTOS, S. A.; CASTRO, A. D. M.; SOARES, D. A. S. R. Empreendedorismo tecnológico como opção de segunda carreira: pós-aposentadoria. Revista de Empreendedorismo e Gestão de Pequenas Empresas, v. 3, n. 2, p. 94-119, 2014. 


\section{Transferência de tecnologia}

Tecnologia é o produto da ação humana, ou seja, é concebida e fisicamente construída por atores trabalhando em um dado contexto social. Esses atores atribuem à tecnologia diferentes significados, enfatizando-os e aplicando-os na sua construção. Uma vez desenvolvida e implantada, a tecnologia tende a tornar-se institucionalizada, perdendo assim sua ligação com os agentes humanos que a construíram ou a deram significado. Por essa razão, a tecnologia parece ser parte das propriedades estruturais objetivas da organização (ORLIKOWSKI; BARLEY, 2001).

A maior dificuldade enfrentada no processo de Pesquisa, Desenvolvimento e Inovação (PD\&I) é a de transformar conhecimentos em tecnologias, produtos e serviços que, incorporados ao processo produtivo, gerem benefícios para o público envolvido e se constituam em inovações. A tecnologia pode ser definida como o conhecimento teórico e prático relativo a certos tipos de ocorrências e atividades associadas à produção e transformação de materiais (ROSENBERG, 1982, BURGELMAN et al., 2004).

Segundo Gilbert e Cordey-Hayes (1996), a chave do sucesso para uma organização ou empresa está incorporada à sua habilidade de implementar, dominar e valorizar conhecimentos tecnológicos. Nesse mesmo sentido, Burgelman et al. (2004, p. 2) ressaltam que "a tecnologia é um recurso de alta relevância a diversas organizações; gerenciar esse recurso para vantagem competitiva significa integrá-lo na estratégia da empresa". Pode-se dizer que a competitividade organizacional exige não apenas o conhecimento tecnológico, mas também o gerenciamento tecnológico.

Cribb (1999) destaca que uma das atividades do gerenciamento tecnológico é a transferência de tecnologia, entendida como o deslocamento do conhecimento tecnológico de um lugar para outro. Tal deslocamento ocorre por meio de negociações não comerciais ou por meio de transações comerciais, envolvendo geralmente atividades de comunicação e interação. O autor evidencia que a transferência de tecnologia não se reduz a atividades de venda e compra dos

DOI: 10.14211regepe3281. FREIRE, J. R. S.; SANTOS, I. C.; SANTOS, S. A.; CASTRO, A. D. M.; SOARES, D. A. S. R. Empreendedorismo tecnológico como opção de segunda carreira: pós-aposentadoria. Revista de Empreendedorismo e Gestão de Pequenas 
produtos, materiais, plantas, máquinas e ferramentas. Ela implica também na mobilização de indivíduos e organizações. Takeuchi e Nonaka (2008) destacam este aspecto, assinalando que o novo conhecimento começa sempre com o indivíduo.

Observa-se, no entanto, que embora seja comumente utilizada a expressão transferência do conhecimento por muitos autores, entende-se que ela não é apropriada, uma vez que o conhecimento é um processo cognitivo inerente às pessoas, não sendo possível transferi-lo e sim associar e compartilhar. Takeuchi e Nonaka (2008) afirmam que a criação do conhecimento ocorre pela interação entre o conhecimento tácito e o explícito, de maneira individual ou coletiva, dentro de um contexto organizacional.

Portanto o empregado empreendedor, desenvolvedor de inovação tecnológica, ao aposentar e deixar a empresa, leva consigo parte do conhecimento e, possivelmente, uma base de dados internalizada e não codificada do conhecimento empírico que construiu ao longo da sua experiência, sendo esta determinante na constituição das vantagens competitivas em um novo negócio.

Como se observa, a transferência de tecnologia não é a imitação passiva de tecnologias oriundas de fontes externas, mas um processo ativo e criativo de adaptação que leva em conta as condições locais de atuação das partes envolvidas. Os mecanismos de transferência de tecnologia são diversos e incluem o licenciamento de tecnologia, acordos cooperativos de P\&D, a assistência técnica, o compartilhamento de uso de equipamentos, programas de troca de tecnologias, dia de campo, publicações e palestras. "Na verdade, a transferência de tecnologia é um processo estrutural de aprendizado" (SANKAT; PUN; MOTILAL, 2007, p. 646).

Embora haja consenso sobre a importância da formação de acervos de conhecimento mesmo sem uma estratégia de continuidade de carreira após a aposentadoria, esse acervo se perde, uma vez que as atividades de disseminação de conhecimento e de geração acabam sendo mitigadas pela ausência do pesquisador no ambiente de PD\&I. Assim, o estímulo ao empreendedorismo pode estabelecer uma continuidade na geração de conhecimento científico, especialmente junto aos aposentados.

DOI: 10.14211regepe3281. FREIRE, J. R. S.; SANTOS, I. C.; SANTOS, S. A.; CASTRO, A. D. M.; SOARES, D. A. S. R. Empreendedorismo tecnológico como opção de segunda carreira: pós-aposentadoria. Revista de Empreendedorismo e Gestão de Pequenas 
Aposentadoria

O avanço da ciência e da tecnologia desencadeia um progressivo aumento da longevidade e da expectativa de vida, proporcionando ao sujeito usufruir um tempo maior de sua existência como aposentado, gozando de boas condições físicas e mentais.

Essa realidade é facilmente constatada no Brasil, pois se vê uma elevação significativa do percentual de aposentados nos últimos anos. Segundo o Instituto Brasileiro de Geografia e Estatística (IBGE, 2010a), em 2002 as pessoas com mais de 60 anos representavam 9,3\% da população brasileira. Atualmente, estão em torno de 10,5\% (crescimento relativo entre 1997 e 2007 de mais do que o dobro do crescimento da população total) e, conforme projeções, em 2020 representarão 11,4 $\%$ do total de brasileiros.

A Organização Mundial de Saúde (OMS), conforme aponta o IBGE (2013), prevê que até 2025 o Brasil será o sexto maior país do mundo em número de idosos. Assim, o efeito social da dinâmica demográfica e reconfiguração do quadro etário nacional oferecem evidências para a constatação da importância da aposentadoria para a reorganização social e, em escala individual, a mudança real e concreta na vida do aposentado.

Moscovici (2000) ensina que podem existir dois cenários distintos no final de carreira. O primeiro diz respeito a um sujeito satisfeito com os resultados profissionais alcançados até o momento, porém há uma preocupação com o pouco tempo que lhe sobra para alcançar mais, levando-o a pensar na aposentadoria como algo limitador e desagradável. O outro diz respeito a um profissional que considerava seu trabalho seguro e estável, e com a chegada da aposentadoria, faz uma avaliação da sua carreira. Nesta avaliação, percebe que não era esta a vida desejada, porém, acha que não há mais tempo para mudar. Esse sentimento pode levar a uma crise existencial e, em alguns casos, até mesmo à depressão.

É importante assinalar que a aposentadoria é um momento de se encarar o mundo do não trabalho assalariado. Este mundo é relativamente diferente do pertencer ou não a uma instituição. O momento requer uma reorganização da vida familiar, novas relações afetivas, novos espaços de convívio e relacionamentos fora 
do mundo do trabalho, novas rotinas e até a diminuição gradativa da jornada diária. Como possibilidades surgem os trabalhos alternativos, hobbies, as experiências em artes e ofícios que geram autonomia em relação à organização do tempo em função do trabalho (CARLOS et al., 1999).

O trabalho exerce influência sobre as pessoas, sendo uma fonte de atividade essencial à sobrevivência e ao desenvolvimento do homem e um núcleo definidor de sua existência. De um modo ou de outro, a vida do indivíduo é baseada no trabalho e o processo de socialização primária e secundária prepara-o para isto (ZANELLI; SILVA; SOARES, 2010). Vários estudos, como os de Morin (2001) e Mow (1987), apontaram que a maioria das pessoas continuaria trabalhando mesmo se tivesse dinheiro suficiente para viver o resto de sua vida.

Para Alvarenga et al. (2007), os valores atribuídos à aposentadoria pelo meio social têm influência acentuada sobre as pessoas, alertando-as sobre a iminente chegada da velhice e, como consequência, o fato de se tornarem economicamente improdutivas, ainda que tenham esse direito. Este aparente rebaixamento dos padrões sociais e da qualidade de vida, contudo, não deveria existir, pois a aposentadoria seria o momento no qual o indivíduo, após anos de dedicação ao trabalho, poderia aproveitar mais, viver mais junto à família e à comunidade, fazer o que não teve tempo de fazer durante sua vida profissional, etc.

O fato é que, se para alguns a aposentadoria é assimilada de forma positiva, proporcionando uma reorganização da vida, para outros é significativamente prejudicial, podendo afetar sua estrutura psíquica. Logo, a alternativa de um processo de empreender uma nova vida e um novo negócio pode proporcionar qualidade de vida a muitos aposentados.

Posta assim a questão, a seguir serão descritos os programas da Empresa Brasileira de Pesquisa Agropecuária (Embrapa) para estímulo ao empreendedorismo.

DOI: 10.14211regepe3281. FREIRE, J. R. S.; SANTOS, I. C.; SANTOS, S. A.; CASTRO, A. D. M.; SOARES, D. A. S. R. Empreendedorismo tecnológico como opção de segunda carreira: pós-aposentadoria. Revista de Empreendedorismo e Gestão de Pequenas 
Uma experiência institucional na formação de EBT

Com a intenção de promover novos arranjos institucionais, visando a inovação por meio da melhoria da eficiência de transferência de tecnologia para a sociedade brasileira, a Empresa Brasileira de Pesquisa Agropecuária (Embrapa) criou o Programa de Apoio ao Desenvolvimento de Novas Empresas de Base Tecnológica e à Transferência de Tecnologia (PROETA) com o apoio do Banco Interamericano de Desenvolvimento/Fundo Multilateral de Investimento (BID/FUMIN). O programa visa a promoção do agronegócio mediante a transferência de tecnologias, produtos e serviços gerados para a iniciativa privada a fim de contribuir para a geração de empresas de base tecnológica por meio da incubação de empresas (EMBRAPA, 2009).

O processo de transferência de tecnologias agropecuárias possibilita aos empreendedores aprenderem a usar as tecnologias adequadas ao bom andamento de seus negócios. "Para que o processo tenha resultado satisfatório, o conhecimento transformado em produtos e serviços precisa ser demonstrado a uma comunidade de usuários por meio de sistemas de produção e, posteriormente, ser transferido à indústria, para que sua utilização socioeconômica torne-se viável“ (MODESTO JÚNIOR, 2006, p. 11).

A iniciativa da instituição em adotar o PROETA evidencia seu interesse em fomentar o desenvolvimento de uma cultura empreendedora. Este programa, no entanto, se estendido aos empregados em fim de carreira, poderia promover o desenvolvimento de estudos e planos de negócios de base essencialmente tecnológica. Tal fato geraria uma postura intraempreendedora no empregado, que acabaria por influenciar o processo de aposentadoria. Serviria, ainda, como ponto de partida para potencializar a identificação e a oportunidade de novos negócios a partir dos projetos em desenvolvimento ou de projetos nas prateleiras.

DOI: 10.14211regepe3281. FREIRE, J. R. S.; SANTOS, I. C.; SANTOS, S. A.; CASTRO, A. D. M.; SOARES, D. A. S. R. Empreendedorismo tecnológico como opção de segunda carreira: pós-aposentadoria. Revista de Empreendedorismo e Gestão de Pequenas 


\section{Metodologia}

Recentemente, gestores de Instituições de pesquisa têm voltado a atenção para o entendimento do processo de transferência de tecnologia, adotando estratégias específicas e incluindo acordos de cooperação, joint venture e outras parcerias. Não obstante isso se observou haver pouca investigação acerca da transferência tecnológica mobilizada pelo incentivo ao empreendedorismo tecnológico junto aos pesquisadores em fase de aposentadoria. Assim, este estudo pretende contribuir para o debate de um tema considerado de alto valor para o ambiente a que se destina discutir.

Para tanto, o presente estudo utiliza uma abordagem quantitativa, baseado em uma pesquisa exploratória, com a finalidade de: aumentar o entendimento do problema gerencial; saber como outras pessoas resolveram problemas similares ao seu; identificar informações que possam ser usadas como questões investigativas; e identificar fontes reais que possam ser usadas como parâmetros de comparação (BARDIN, 1995).

Ao se definir o universo da pesquisa, precisa-se tratar da amostra, podendo esta ser probabilística ou não probabilística. Vale registrar que a amostra, para uma pesquisa quantitativa, "é um subgrupo da população da qual se coletam os dados e que deve ser representativo de tal população" (SAMPIERI; COLLADO; LUCIO, 2003, p. 302).

\section{Lócus, amostra da pesquisa e técnicas para a coleta de dados}

O universo da pesquisa é constituído pelos gestores e empregados em processo de aposentadoria e os já aposentados pelas Instituições de Pesquisa aplicada de Instituições Públicas. Considerou-se uma Instituição de Pesquisa e desenvolvimento com atuação nacional e três Instituições de Pesquisa e Extensão com atuação estadual.

O instrumento de coleta de dados foi preparado com base nos dados estabelecidos a priori pelo pesquisador. Desta forma, elaborou-se dois questionários

DOI: 10.14211regepe3281. FREIRE, J. R. S.; SANTOS, I. C.; SANTOS, S. A.; CASTRO, A. D. M.; SOARES, D. A. S. R. Empreendedorismo tecnológico como opção de segunda carreira: pós-aposentadoria. Revista de Empreendedorismo e Gestão de Pequenas 
de múltiplas escolhas. A amostra utilizada na coleta de dados foi selecionada de forma intencional ou, como definem Dess, Lumpkin e Covin (1997), trata-se de uma amostra subjetiva. Isto é, um tipo de amostra direcionada e usada em pesquisas exploratórias, nas quais o pesquisador seleciona uma amostra que atenda a determinados critérios previamente especificados.

A técnica utilizada para a coleta de dados foi uma pesquisa do tipo survey, sendo possível aplicá-la a um grupo homogêneo com pelo menos uma característica em comum como, neste caso, pertencer a uma Instituição de Pesquisa (FLYNN et al., 1990). O instrumento de pesquisa foi disponibilizado no aplicativo do google drive, que funciona totalmente online.

O questionário apresenta uma escala de avaliação com nota de 1 a 7 , sendo que a nota 1 (um) é pouco desejável e a nota 7 muito desejável. A coleta dos dados da pesquisa compreende quatro etapas para análise do caso: na primeira etapa foi realizado um pré-teste com 2 (dois) empregados aposentados que saíram da instituição, 9 (nove) empregados aposentados que permanecem trabalhando na instituição e com 1 (um) Gestor de Centro de Pesquisa para os devidos ajustes no instrumento de pesquisa.

Na segunda etapa, o questionário foi encaminhado para a instituição com atuação nacional e para as três Instituições de Pesquisa e extensão com atuação estadual, utilizando-se de uma lista de e-mails dos aposentados da instituição. Os itens dos questionários de múltipla escolha e com a devida escala pode ser visualizado no Quadro 3. Para as opções de resposta visualizadas no Quadro 3, foi realizada uma questão básica aos respondentes: quando você estava próximo de se aposentar e deixar a empresa, pensava em ocupar o tempo livre, como? Responda atribuindo uma nota de $\mathbf{1}$ a 7 a cada item abaixo, onde 1 representa a nota pouco desejável e 7 a nota muito desejável:

DOI: 10.14211regepe3281. FREIRE, J. R. S.; SANTOS, I. C.; SANTOS, S. A.; CASTRO, A. D. M.; SOARES, D. A. S. R. Empreendedorismo tecnológico como opção de segunda carreira: pós-aposentadoria. Revista de Empreendedorismo e Gestão de Pequenas 


\begin{tabular}{|c|c|c|c|c|c|c|c|c|}
\hline $\mathrm{N}^{\circ}$ & Questões & \multicolumn{7}{|c|}{ Escala } \\
\hline & & 1 & 2 & 3 & 4 & 5 & 6 & 7 \\
\hline 1 & Criando meu próprio negócio. & & & & & & & \\
\hline 2 & Descansando, viajando e outros. & & & & & & & \\
\hline 3 & Desenvolvendo um trabalho como voluntário em outra Instituição. & & & & & & & \\
\hline 4 & $\begin{array}{l}\text { Prestando serviço de consultoria especializada (microempresa) para os } \\
\text { projetos em andamento na Instituição. }\end{array}$ & & & & & & & \\
\hline 5 & Trabalhando como voluntário na Instituição na qual me aposentei. & & & & & & & \\
\hline 6 & $\begin{array}{l}\text { Desenvolvendo uma parceria técnica para prestação de serviço de extensão } \\
\text { a pesquisa. }\end{array}$ & & & & & & & \\
\hline 7 & $\begin{array}{l}\text { Criando uma empresa e incubando-a (desenvolvendo) dentro da } \\
\text { Instituição. }\end{array}$ & & & & & & & \\
\hline 8 & $\begin{array}{l}\text { Trabalhando para captação de recursos em eventos e projetos para a } \\
\text { Instituição na qual me aposentei. }\end{array}$ & & & & & & & \\
\hline 9 & $\begin{array}{l}\text { Participando de seminários, mesas redondas, reuniões técnicas para a } \\
\text { Instituição na qual me aposentei. }\end{array}$ & & & & & & & \\
\hline 10 & $\begin{array}{l}\text { Recebendo convite para ser coautor de projetos e artigos científicos para a } \\
\text { Instituição na qual me aposentei. }\end{array}$ & & & & & & & \\
\hline 11 & Orientando bolsista para a Instituição na qual me aposentei. & & & & & & & \\
\hline 12 & $\begin{array}{l}\text { Capacitando novos empregados voluntariamente (sem remuneração) para a } \\
\text { Instituição na qual me aposentei. }\end{array}$ & & & & & & & \\
\hline 13 & De outra maneira. Especifique-a e de a nota: & & & & & & & \\
\hline
\end{tabular}

QUADRO 3 - Questionários Aplicados aos Aposentados

Fonte: Elaborado pelos Autores (2014).

$\mathrm{Na}$ terceira etapa, foi repetido o procedimento de coleta de dados encaminhando o questionário para 36 Gestores de Centro de Pesquisa Aplicada, solicitando que atribuíssem uma nota de 1 a 7 para cada item. A nota 7 representa extremamente importante e a nota 1 mínima importância. Os itens do questionário podem ser visualizados no Quadro 4.

As questões 1, 2 e 3 foram elaboradas para saber se o problema existe e se a instituição está disposta a acolher o empregado após a aposentadoria:

1. Existem situações em que o empregado aposentado tem dificuldade em deixar a instituição?

2. O empregado ao deixar a empresa devido a sua aposentadoria acarreta um problema para a instituição, com perda de sua experiência e do conhecimento científico?

3. A instituição estaria disposta a acolher o empregado que quisesse continuar em projetos específicos como opção de segunda carreira, após sua aposentadoria?

DOI: 10.14211regepe3281. FREIRE, J. R. S.; SANTOS, I. C.; SANTOS, S. A.; CASTRO, A. D. M.; SOARES, D. A. S. R. Empreendedorismo tecnológico como opção de segunda carreira: pós-aposentadoria. Revista de Empreendedorismo e Gestão de Pequenas 
 \\ A Revista da ANEGEPE}

\begin{tabular}{|c|c|c|c|c|c|c|c|c|}
\hline № & Questões & \multicolumn{7}{|c|}{ Escala } \\
\hline & & 1 & 2 & 3 & 4 & 5 & 6 & 7 \\
\hline 1 & $\begin{array}{l}\text { Capacitação de empreendedorismo como processo de preparação de } \\
\text { aposentadoria. }\end{array}$ & & & & & & & \\
\hline 2 & $\begin{array}{l}\text { Programa de voluntariado, aos ex-empregados como opção na } \\
\text { prestação de serviço a Instituição (capacitando novos empregados, } \\
\text { orientando bolsistas, instrutoria, coaching e outros) }\end{array}$ & & & & & & & \\
\hline 3 & $\begin{array}{l}\text { Programa que permite aos ex-empregados (empreendedor } \\
\text { tecnológico) continue trabalhando em seu projeto de pesquisa, } \\
\text { mediante celebração de contratos. }\end{array}$ & & & & & & & \\
\hline 4 & $\begin{array}{l}\text { Estimular o empregado em processo de aposentadoria a criação de } \\
\text { empresa a partir de uma tecnologia desenvolvida na Instituição (spin- } \\
\text { off) com as devidas parcerias estabelecidas. }\end{array}$ & & & & & & & \\
\hline 5 & $\begin{array}{l}\text { Estimular o ex-empregado a criação de empresa para formatar } \\
\text { parceria, utilizando uma tecnologia desenvolvida na organização. } \\
\text { (spin-in) }\end{array}$ & & & & & & & \\
\hline 6 & $\begin{array}{l}\text { Estimular o empregado em processo de aposentadoria para quando } \\
\text { aposentado, criar empresas de base tecnológicas para aportar } \\
\text { tecnologia nos Programa de Incubadoras existentes. Tecnologia que a } \\
\text { empresa desenvolveu e não quer mais essa tecnologia. (spin-out) }\end{array}$ & & & & & & & \\
\hline 7 & $\begin{array}{l}\text { Programa "Prata da Casa" o ex-empregado recebe um crachá prata, } \\
\text { para adentrar a Instituição e visitar os colegas e participar de } \\
\text { festividade e palestras. }\end{array}$ & & & & & & & \\
\hline 8 & $\begin{array}{l}\text { Criação de um Programa de Serviços Tecnológicos, incluindo o apoio } \\
\text { à transferência de tecnologia e a implementação de modelos locais de } \\
\text { incubação de empresas. }\end{array}$ & & & & & & & \\
\hline 9 & Outros: especifique-a e de a nota. & & & & & & & \\
\hline
\end{tabular}

QUADRO 4 - Questionários Aplicados aos Gestores

Fonte: Elaborados pelos Autores (2014).

Cabe aqui destacar que o caminho traçado nesta pesquisa para atingir seu objetivo busca resgatar a política de recursos humanos nas instituições, desenvolvendo um programa de empreendedorismo para preparar o empregado ou servidor dando-lhe opção de uma segunda carreira.

Assim sendo, pretende-se confrontar os principais conceitos teóricos que envolvem o empreendedorismo e as estratégias das Instituições de Pesquisa com a preocupação com seus empregados aposentados, sugerindo uma estratégia corporativa para estimular o empreendedorismo corporativo, ou interno, como meio de transferência de tecnologia.

\section{Análise dos resultados}

Para se chegar aos resultados, apoiando-se na metodologia referenciada e nas fundamentações teóricas, o primeiro passo foi verificar pelas respostas dos

DOI: 10.14211regepe3281. FREIRE, J. R. S.; SANTOS, I. C.; SANTOS, S. A.; CASTRO, A. D. M.; SOARES, D. A. S. R. Empreendedorismo tecnológico como opção de segunda carreira: pós-aposentadoria. Revista de Empreendedorismo e Gestão de Pequenas Empresas, v. 3, n. 2, p. 94-119, 2014. 
gestores se os seguintes problemas existem: a) o empregado aposentado tem dificuldade em deixar a instituição; b) perda do conhecimento científico; e c) se a instituição estaria disposta a acolher o aposentado como opção de segunda carreira. Para este último, 100\% dos respondentes disseram sim, que o problema existe.

Considerando a existência do problema como condição essencial para a validação da pesquisa, passou-se para a apuração das respostas aos questionários.

Foram aplicadas questões a fim de verificar a visão dos gestores dos Institutos de Pesquisa quanto à abordagem corporativa. Dos 36 questionários enviados, $17 \%$ (dezessete por cento) retornaram. Os respondentes são predominantemente do sexo masculino (70,58\%), contando com $29,42 \%$ de respondentes do sexo feminino. Do total dos respondentes:

- $82,36 \%$ são doutores;

- $11,76 \%$ são mestres;

- $5,88 \%$ têm especialização.

Em relação ao tempo de trabalho em atividades de Pesquisa, Desenvolvimento e Inovação (PD\&I), constatou-se que 64,70\% possuem mais de 20 anos, 23,53\% têm entre 10 a 20 anos e 11,77\% estão entre 5 a 10 anos.

Dos 36 questionários aplicados aos aposentados dos Institutos de Pesquisa, houve um retorno de $66.66 \%$. Os respondentes são na maioria do sexo masculino $(60,37 \%)$ e $39,63 \%$ do sexo feminino. Do total de respondentes:

- $47,16 \%$ são doutores, entre eles 4 (quatro) foram gestores de PD\&I;

- $15,10 \%$ são mestres, entre eles 2 (dois) foram gestores de PD\&I;

- 22,64\% possuem nível superior;

- $15,10 \%$ possuem nível médio

$\mathrm{Na}$ questão feita para os aposentados: você gostaria de continuar (ou ter continuado) desenvolvendo seu projeto/trabalho após sua aposentadoria, prestando serviço para a sua instituição? $75 \%$ responderam sim, que gostariam de ter continuado, $15 \%$ não gostariam e 10\% responderam que talvez continuassem auxiliando a instituição.

DOI: 10.14211regepe3281. FREIRE, J. R. S.; SANTOS, I. C.; SANTOS, S. A.; CASTRO, A. D. M.; SOARES, D. A. S. R. Empreendedorismo tecnológico como opção de segunda carreira: pós-aposentadoria. Revista de Empreendedorismo e Gestão de Pequenas 


\section{A Revista da ANEGEPE \\ www.regepe.org.br}

Aos gestores perguntou-se: quais programas contribuiriam para estimular o empreendedorismo? Para esta pergunta, 15\% dos respondentes destacaram a capacitação empreendedora dos pesquisadores em processo de aposentadoria, $13 \%$, a criação de empresas de bases tecnológicas a partir de uma tecnologia desenvolvida na instituição (spin-off). Na mesma proporção de respostas, foram apontadas como ações importantes: a criação da empresa por um pesquisador externo, mas utilizando uma tecnologia desenvolvida na instituição (spin-in); e aposentar e continuar trabalhando na empresa.

A pequena variação entre as respostas não permitiu estabelecer de forma assertiva qual seria a ação de maior importância. Todavia, nas questões em que desdobramentos são destacados na forma de abertura de pessoa jurídica, tais como spin-off, spin-in, spin-out, observa-se haver aceitação pelos gestores pesquisados, em estimular uma política de empreendedorismo tecnológico como opção de segunda carreira.

Para melhor compreensão, o Gráfico 1 apresenta as distribuições dessas respostas:

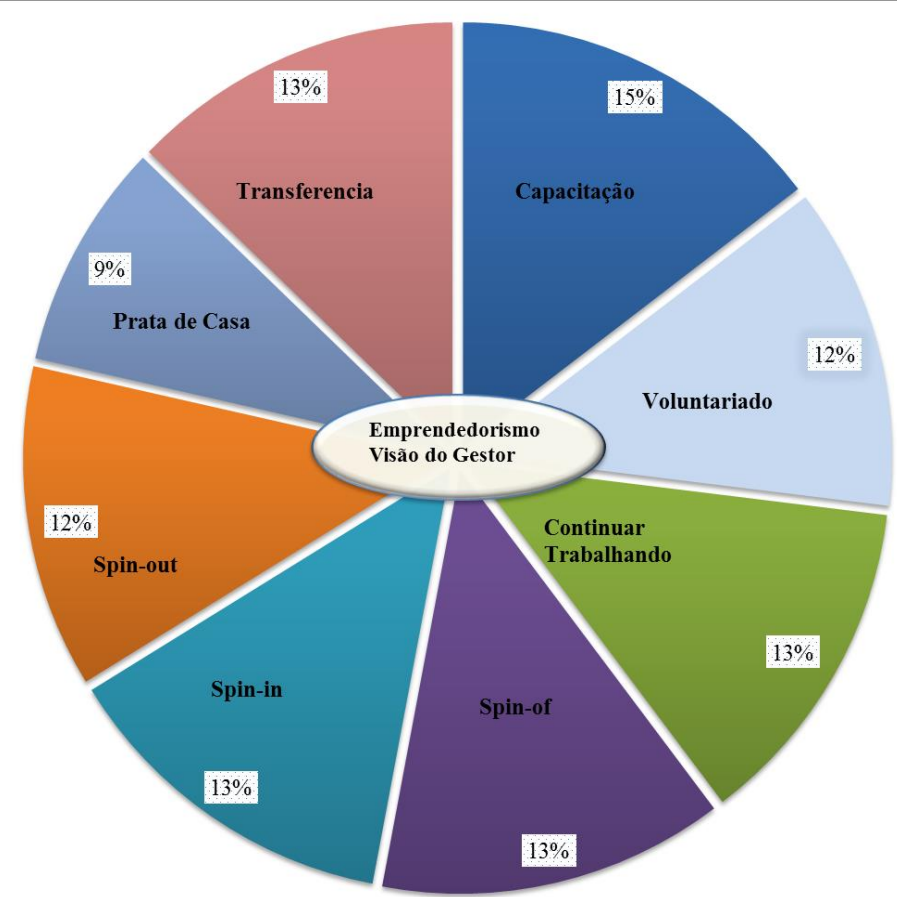

GRÁFICO 1 - Empreendedorismo como Opção de Segunda Carreira: Visão do Gestor Fonte: Os Autores (2014).

DOI: 10.14211regepe3281. FREIRE, J. R. S.; SANTOS, I. C.; SANTOS, S. A.; CASTRO, A. D. M.; SOARES, D. A. S. R. Empreendedorismo tecnológico como opção de segunda carreira: pós-aposentadoria. Revista de Empreendedorismo e Gestão de Pequenas 
Com o intuito de reduzir a limitação da pesquisa e o amplo conjunto de variáveis a um número menor de fatores, foi realizado uma análise fatorial para definir as principais opções dos gestores. O procedimento estatístico de análise fatorial com o intuito de reduzir um amplo conjunto de variáveis a um número menor de fatores pode ser caracterizado como dimensões de atributo avaliado (HAIR et al., 2005).

As análises fatoriais exploratórias aplicadas tiveram como método a extração de componentes principais sobre a matriz de correlações. Foi efetuada a rotação ortogonal varimax com a finalidade de eliminar os coeficientes com valores absolutos menores que 0,30 . Este método é considerado apropriado quando se busca redução do número de itens de uma escala (ROMEIRO, 2012). Foi necessário, ainda, excluir os itens redundantes ou com baixo poder de explicação para melhorar a análise. Considerando uma seleção de cargas fatoriais mais robustas, optou-se pela exclusão das variáveis de cargas abaixo de 0,70.

Ao utilizar o critério do autovalor superior a 1,0, que representa 96,29\% do ponto de vista das variáveis (gestores), conforme componente de rotação varimax, a solução final da análise fatorial indicou três fatores. As variáveis agrupadas em suas respectivas dimensões e cargas fatoriais formam três dimensões, conforme Tabela 1:

TABELA 1 - Carga Fatorial - Gestores

Total Variance Explained

\begin{tabular}{|c|c|c|c|c|c|c|c|c|c|}
\hline \multirow[t]{2}{*}{ Component } & \multicolumn{3}{|c|}{ Initial Eigenvalues } & \multicolumn{3}{|c|}{ Extraction Sums of Squared Loadings } & \multicolumn{3}{|c|}{ Rotation Sums of Squared Loadings } \\
\hline & Total & $\%$ of Variance & Cumulative \% & Total & $\%$ of Variance & Cumulative \% & Total & $\%$ of Variance & Cumulative $\%$ \\
\hline 1 & 3,682 & 46,021 & 46,021 & 3,682 & 46,021 & 46,021 & 3,339 & 41,741 & 41,741 \\
\hline 2 & 2,544 & 31,804 & 77,824 & 2,544 & 31,804 & 77,824 & 2,756 & 34,446 & 76,187 \\
\hline 3 & 1,478 & 18,472 & 96,296 & 1,478 & 18,472 & 96,296 & 1,609 & 20,109 & 96,296 \\
\hline 4 & ,296 & 3,704 & 100,000 & & & & & & \\
\hline 5 & $2,341 \mathrm{E}-16$ & $2,926 \mathrm{E}-15$ & 100,000 & & & & & & \\
\hline 6 & $3,857 \mathrm{E}-17$ & $4,822 \mathrm{E}-16$ & 100,000 & & & & & & \\
\hline 7 & $-1,855 E-16$ & $-2,319 E-15$ & 100,000 & & & & & & \\
\hline 8 & $-2,336 \mathrm{E}-16$ & $-2,920 \mathrm{E}-15$ & 100,000 & & & & & & \\
\hline
\end{tabular}

Extraction Method: Principal Component Analysis.

Fonte: Os Autores (2014).

DOI: 10.14211regepe3281. FREIRE, J. R. S.; SANTOS, I. C.; SANTOS, S. A.; CASTRO, A. D. M.; SOARES, D. A. S. R. Empreendedorismo tecnológico como opção de segunda carreira: pós-aposentadoria. Revista de Empreendedorismo e Gestão de Pequenas 
Os três fatores que explicam o ponto de vista dos gestores, após a matriz rotacionada foram:

- Capacitação de empreendedorismo dos empregados como processo de preparação de aposentadoria;

- Desenvolver um programa de voluntariado pós-aposentadoria;

- Política da empresa que permita aos ex-empregados continuarem trabalhando em seus projetos de pesquisas.

O teste de adequação de amostragem Kmo equivaleu a 0,627 (considerado acima do nível mínimo aceitável de 0,50) e o teste de esfericidade de Bartlett rejeitou a hipótese nula, onde as correlações entre as variáveis originais eram iguais a 0 (zero) com $p$-value maior que 0,00001 , conforme visualizado na Tabela 2 :

TABELA 2 - Teste de Adequação de Amostragem

KMO and Bartlett's Test ${ }^{a}$

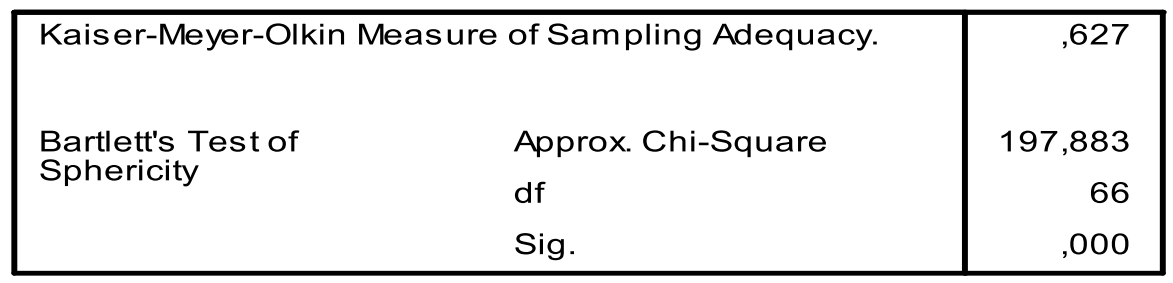

a. Based on correlations

Fonte: Os Autores (2014).

A possibilidade de sucesso da transferência é ampliada de forma significativa quando a empresa é criada com a participação de algum pesquisador envolvido com o grupo de pesquisa que originou a tecnologia. A participação desse pesquisador acaba servindo de elo entre o grupo de pesquisa e a empresa, facilitando o processo de finalização da tecnologia, o que é positivo para a empresa e para o laboratório de P\&D (PERUSSI FILHO; BISCEGLI, 2007).

Os procedimentos foram repetidos nas questões aplicadas aos aposentados. Ou seja, pesquisa do tipo survey em lista de e-mails dos aposentados das instituições pesquisadas. A pesquisa conta com $66 \%$ dos respondentes de um total de 36 questionários aplicados. Fez-se a seguinte pergunta: quando você estava próximo de se aposentar e deixar a empresa, pensava em ocupar o tempo livre

DOI: 10.14211regepe3281. FREIRE, J. R. S.; SANTOS, I. C.; SANTOS, S. A.; CASTRO, A. D. M.; SOARES, D. A. S. R. Empreendedorismo tecnológico como opção de segunda carreira: pós-aposentadoria. Revista de Empreendedorismo e Gestão de Pequenas 
como? Para esta pergunta, foram oferecidas 12 opções variadas de atividades após a aposentadoria com uma escala de 1 (pouco desejável) a 7 (muito desejável).

Procedeu-se o tratamento dos dados com procedimento estatístico para a verificação dos percentuais a fim de compreender como os aposentados desejam ocupar o tempo pós-aposentadoria. Conforme a Gráfico 2, observa-se que os aposentados destacaram o descanso com um percentual de 95\% de intenção, ser voluntários em outra instituição 93\%, estabelecendo parceria técnica para prestação de serviço de extensão e pesquisa com a preferência de $80 \%$ dos respondentes, participando de seminários e reuniões com percentual de $72 \%$, prestando serviços de consultoria e participando em coautoria de projetos com um percentual de $66 \%$ e um percentual de $75 \%$ dos respondentes desejam abrir o seu próprio negócio.

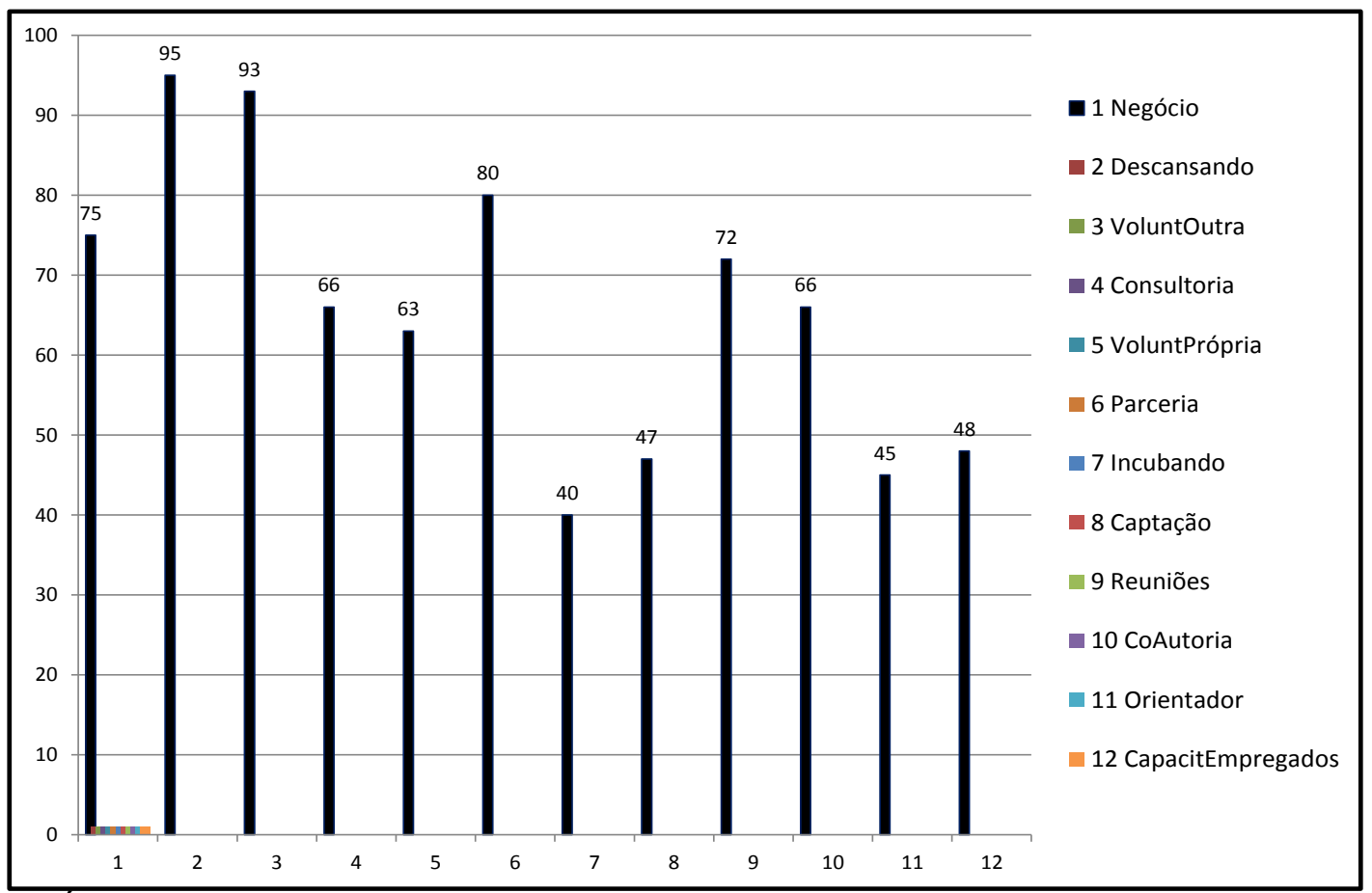

GRÁFICO 2 - Resultados Apresentados aos Aposentados da Instituição de Pesquisa Fonte: Os Autores (2014).

A partir dos dados apresentados pela pesquisa, observou-se que a maioria dos respondentes estão dispostos a continuar trabalhando, mesmo sendo voluntários em outras instituições. Observou-se também uma atitude 
empreendedora, com o desejo de continuarem desenvolvendo seus projetos de pesquisas.

Aplicou-se a análise fatorial exploratória com o método de extração de componentes principais sobre a matriz de correlações e efetuando a rotação varimax com a finalidade de eliminar os coeficientes com valores absolutos menores que 0,30. O teste de amostragem Kmo equivaleu a 0,888 (considerado acima do nível mínimo aceitável de 0,50 ) e o teste de Bartlett rejeitou a hipótese nula, conforme pode ser visualizado na Tabela 3:

TABELA 3 - Teste de Adequação de Amostragem

KMO and Bartlett's Test

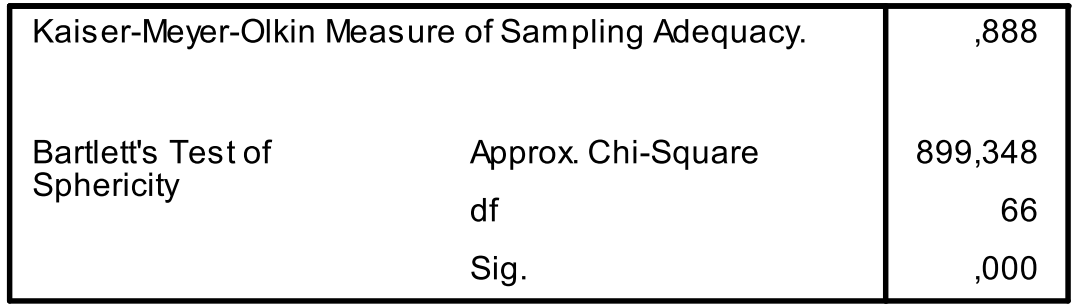

Fonte: Os Autores (2014).

A análise fatorial, ao utilizar o critério do autovalor superior a 1,0 que representa 99,65\% do ponto de vista dos aposentados, indicou dois fatores:

- Participações em seminários e reuniões, desenvolvendo parcerias técnica para projeto de extensão de pesquisa;

- Capacitando novos empregados e participando em coautoria em projetos de pesquisa e artigos científicos.

De acordo com a análise, pode-se inferir que o espírito empreendedor como opção de segunda carreira pós-aposentadoria está presente nos pesquisados em estudo. Isto representa uma grande oportunidade para a Instituição de Pesquisa criar estratégias de transferência de tecnologia.

\section{Considerações finais}

As ferramentas estatísticas, em nível de análise exploratória de dados, assegurou que a aplicação da análise fatorial para esse conjunto de dados foi 
adequada para a determinação das variáveis relativas à escala de desejabilidade do empreendedor pós-aposentadoria e o reconhecimento da importância do gestor em relação à aplicação de uma política de recursos humanos ao empreendedorismo tecnológico como opção de segunda carreira.

Pode-se concluir com a presente pesquisa que o objetivo principal foi atingido, pois conseguiu demonstrar a base do empreendedorismo tecnológico desejável entre os gestores e aposentados das Instituições de Pesquisa. Observouse a existência de iniciativa estratégica corporativa no processo de transferência de tecnologia aos empregados pós-aposentadoria com um programa de qualidade de vida com empreendedorismo como opção de segunda carreira.

Diante de todas as observações realizadas nesta pesquisa, recomenda-se uma estratégia corporativa associada ao programa de qualidade de vida, com estímulo aos empregados em processo de aposentadoria e criação de empresa a partir de uma tecnologia interna na qual a instituição não tenha a tecnologia como estratégia da organização, assim como um spin-off ou uma spin-in.

A pesquisa proporcionou também algumas sugestões para ampliar a cultura empreendedora para a participação dos empregados, não como um fim de carreira, mas como um recomeço de um plano de negócio com base essencialmente tecnológica e balizador na vida profissional de um empregado aposentado ou não. Assim, é possível desenvolver uma postura intraempreendedora entre os empregados, compartilhando seus conhecimentos tácitos e explícitos.

Sugere-se que continuem sendo realizados estudos com essa população com uma proposta de continuidade no desenvolvimento dos projetos de pesquisa, na transferência de tecnologia para a sociedade e como reconstrução dos aposentados na acumulação da experiência e do conhecimento, não como um vínculo empregatício, mas como um empreendedor tecnológico em potencial. Outra sugestão de estudo é analisar o perfil demográfico do gestor em relação à faixa etária, tempo de serviço, sexo e se possui características intraempreendedoras.

Por fim, espera-se que os resultados apresentados e analisados neste artigo possam auxiliar na definição ou reformulação de políticas e normas corporativas

DOI: 10.14211regepe3281. FREIRE, J. R. S.; SANTOS, I. C.; SANTOS, S. A.; CASTRO, A. D. M.; SOARES, D. A. S. R. Empreendedorismo tecnológico como opção de segunda carreira: pós-aposentadoria. Revista de Empreendedorismo e Gestão de Pequenas 
favoráveis ao empreendedorismo como opção de segunda carreira nas Instituições de Pesquisa.

\section{Referências:}

ALVARENGA, N. L.; KYAN, L.; BITENCOURT, B.; WANDERLEY, S. K. Repercussões da aposentadoria na qualidade de vida do idoso. Revista de Escola de Enfermagem da USP, São Paulo, v. 34, n. 4, p. 796-802, dez. 2009.

BARDIN, L. Análise de Conteúdo. Lisboa: Edições 70 Ltda., 1995, 288 p.

BORGES, C. Saberes docentes: diferentes tipologias e Classificações de um campo de pesquisa. Revista Educação \& Sociedade, São Paulo, v. 22, n. 74, p. 59-76, abr. 2001.

BURGELMAN, R. A.; CHRISTENSEN, C. H.; WHEELWRIGHT, S. C. Strategic management of technology and innovation. 4 ed. Boston: McGraw Hill, 2004, 336 p.

CARAYANNIS, E.; ROGERS, E. M.; KURIHARA, K.; ALLBRITTON, M. M. High technology spin-offs from government R\&D Laboratories and research institutes. Technovation, v. 18, n. 1, p. 1-10, 1998.

CARLOS, S. A.; JACQUES, M. G. C.; LARRATEA, S. V.; HEREDIA, O. C. Identidade, aposentadoria e terceira idade. Estudos Interdisciplinares sobre Envelhecimento, Porto Alegre, v. 1, p. 77-89, 1999.

CÔRTES, M. R.; PINHO, M.; FERNANDES, A. C.; SMOLKA, R. B.; BARRETO, A. L. C. M. Cooperação em empresas de base tecnológica: uma primeira avaliação baseada numa pesquisa abrangente. São Paulo em Perspectiva, São Paulo, v. 19, n. 1, p. 85-94, mar. 2005.

CRIBB, A. Y. Determinantes da transferência de tecnologia na agroindústria brasileira de alimentos: identificação e caracterização. Journal of Technology Management \& Innovation, Santiago, v. 4, n. 3, p. 89-100, oct. 2009.

DESS, G. G.; LUMPKIN, G.T.; COVIN, J. G. Entrepreneurial Strategy Making and Firm Performance: Tests of Contingency and Configurational Models. Strategic Management Journal, v. 18, n. 9, p. 677-695, oct. 1997.

DORNELAS J.C.A. Empreendedorismo Corporativo: Como ser Empreendedor, inovar e se diferenciar na sua empresa. 3aㅡ ed. Rio de janeiro: Elsevier, 2003, 243 p.

DOI: 10.14211regepe3281. FREIRE, J. R. S.; SANTOS, I. C.; SANTOS, S. A.; CASTRO, A. D. M.; SOARES, D. A. S. R. Empreendedorismo tecnológico como opção de segunda carreira: pós-aposentadoria. Revista de Empreendedorismo e Gestão de Pequenas Empresas, v. 3, n. 2, p. 94-119, 2014. 
DORNELAS. J. C. A. Empreendedorismo corporativo: conceitos e aplicações. Revista de Negócios, Blumenau, v. 9, n. 2, p. 81-90, abr./jun. 2004.

EMBRAPA. Empresa Brasileira de Pesquisa Agropecuária. Programa de Apoio ao Desenvolvimento de Novas Empresas de Base Tecnológica e à Transferência de Tecnologia. Disponível em: <http://hotsites.sct.embrapa.br/proeta/o-que-e-oproeta>. Acesso em 20 maio 2013

FILION, L. J. O empreendedorismo como tema de estudos superiores. In: Empreendedorismo: ciência, técnica e arte. Brasília: CNI/IEL, 2000, p. 13-42.

FLYNN, B. B.; SAKAKIBARA, S. S.; SCHROEDER, R. G.; BATES, K. A.; FLYNN, E. J. Empirical research methods in operations management. Journal of Operations Management, v. 9, n. 2. abr. 1990.

GILBERT, M.; CORDEY-HAYES, M. Understanding the process of knowledge transfer to achieve successful technological innovation. Technovation, Cranfield, v.16, n. 6, p. 301-312, jun. 1996.

HAIR, J.F.; BLACK, W.; BABIN, B.J.; ANDERSON, R.E.; TATHAM, R.L. Análise multivariada de dados. 5.ed. Porto Alegre: Bookman, 2005, 688 p.

IBGE. Instituto Brasileiro de Geografia e Estatística. Banco de Dados Agregados. Sistema IBGE de Recuperação Automática - SIDRA. 2010a. Disponível em: $<\mathrm{http}$ ://saladeimprensa.ibge.gov.br/noticias?view=noticia\&id=1\&busca=1 \&idnoticia $=1$ 766>. Acesso em 20 mai. 2013.

Atlas do Censo Demográfico. 2010b. Disponível em: <http://biblioteca.ibge.gov.br/visualizacao/livros/liv64529.pdf>. Acesso em 06 jul. 2013.

Síntese dos Indicadores Sociais: uma análise das condições de vida da população brasileira 2013. Série Estudos \& Pesquisas. Informação Demográfica e Socioeconômica, v. 32. Rio de Janeiro, 2013. Disponível em <http://biblioteca.ibge.gov.br/visualizacao/livros/liv66777.pdf>. Acesso em 06 jul. 2013.

MAGNANI, M. Identificação de fatores críticos de sucesso para formulação de estratégias que minimizem a perda de competência organizacional de um centro de P\&D agropecuário. 2004, 208 f. Tese (Doutorado em Engenharia de Produção) - Faculdade de Engenharia de Produção e Sistemas, Universidade Federal de Santa Catarina, Florianópolis, 2004.

MCCLELLAND, D. C. Identifying competencies with behavioral-event interviews. Psychological science, v. 9, n. 5, p. 331-339, set. 1998.

DOI: 10.14211regepe3281. FREIRE, J. R. S.; SANTOS, I. C.; SANTOS, S. A.; CASTRO, A. D. M.; SOARES, D. A. S. R. Empreendedorismo tecnológico como opção de segunda carreira: pós-aposentadoria. Revista de Empreendedorismo e Gestão de Pequenas 
MENCK, A. C. M; OLIVEIRA FILHO, J. B. Alternativas de implantação para novas empresas de base tecnológica, 2009. Disponível em: $<$ https://bibliotecadigital.icesi.edu.co/biblioteca_digital/bitstream/item/1928/1/42.pdf>. Acesso em 20 mai. 2013.

MODESTO JÚNIOR, M. S. A incubação de empresa como processo de transferência de tecnologia. Série Documentos 272. Belém do Pará: Embrapa Amazônia Oriental, 2006. 41 p.

MORIN, E. Os sentidos do trabalho. Revista de Administração de Empresas, São Paulo, v. 41, n. 3, p. 8-19, jul./set. 2001.

MOSCOVICI, F. Renascença Organizacional: a revalorização do homem frente à tecnologia para o sucesso da nova empresa. São Paulo: José Olympio, 2000, 129 p.

MOW, International Research Team. The meaning of working. New York: Academic Press, 1987.

TAKEUCHI, H; NONAKA, I. Gestão do conhecimento. Porto Alegre: Bookman, 2008, 319p.

OLIVEIRA. J. B. Empreendedorismo: transformando ideias, informações, tecnologias e modelos de gestão em negócios (processos, produtos e serviços). II SIMPÓSIO INTERNACIONAL DE PRODUÇÃO DE GADO DE CORTE, Uberlândia. Anais... Uberlândia: 2008, p. 245-262.

ORLIKOWSKI, W. J.; BARLEY, S. R. Technology and institutions: what can research on information technology and research on organizations learn from each other? MIS Quarterly, Minneapolis, v. 25, n. 2, p. 145-165, jun. 2001.

PEREIRA, F. M; BERA, G. M. Potencial para criação de empreendimentos de base tecnológicas com os conhecimentos gerados em pesquisa. Economia \& Tecnologia - UFPR, ano 05, v.16, p. 143-150, jan./mar. 2009.

PEREZ PEREZ, M.; SANCHEZ, A. M. The development of university spin-offs: early dynamics of technology transfer and networking. Technovation, v. 23, n. 10, p.823831, out. 2003.

PERUSSI FILHO, S.; BISCEGLI, C. I. Criação de novas empresas de base tecnológica via transferência de tecnologias: reflexões sobre o potencial de sucesso do processo de transferência. In: ENCONTRO NACIONAL DE ENGENHARIA DE PRODUÇÃO, 27, 2007, Foz do Iguaçu, PR; A energia que move a produção: um diálogo sobre integração, projeto e sustentabilidade. Anais... 2007. p. 1-9. 1 CDROM., 2008.

ROBERTS, E. B. Entrepreneurs in high technology. New York: Oxford University Press, 1991. $385 \mathrm{p}$.

DOI: 10.14211regepe3281. FREIRE, J. R. S.; SANTOS, I. C.; SANTOS, S. A.; CASTRO, A. D. M.; SOARES, D. A. S. R. Empreendedorismo tecnológico como opção de segunda carreira: pós-aposentadoria. Revista de Empreendedorismo e Gestão de Pequenas 


\section{A Revista da ANEGEPE

ROMEIRO, M. C. Notas de Aula. Pesquisa Quantitativa em Administração. Programa de Pós-graduação da Universidade Municipal de São Caetano do Sul. São Paulo, 2012.

ROSENBERG, N. Inside the black box: technology and economics. Cambridge: Cambridge University Press, 1982, 305 p.

SAMPIERI, R. H.; COLLADO C. F.; LUCIO, P. B. Metodología de la investigación. 3 ed. México: McGraw Hill, 2003. 850 p.

SANKAT, C. K.; PUN, K. F.; MOTILAL, C. B. Technology transfer for agro-industries in developing nations: a Caribbean perspective. International Journal Agricultural Resources, Governance and Ecology, v. 6, n. 6, p. 642-665, ago. 2007.

SANTOS, S. A; CUNHA, N.C.V. Criação de empresas de base tecnológica: conceitos, instrumentos e recursos. São Paulo: Unicorpore, 2004, 180 p.

SCHUMPETER, J. A. Teoria do desenvolvimento econômico: uma investigação sobre lucros, capital, credito, juro e o ciclo econômico. São Paulo: Abril Cultural, 1982.

ZANELLI, J. C.; SILVA, N.; SOARES, D. H. P.; Orientação para a aposentadoria nas organizações de trabalho: construção de projetos para o pós-carreira. Porto Alegre: Artmed, 2010, 80 p.

DOI: 10.14211regepe3281. FREIRE, J. R. S.; SANTOS, I. C.; SANTOS, S. A.; CASTRO, A. D. M.; SOARES, D. A. S. R. Empreendedorismo tecnológico como opção de segunda carreira: pós-aposentadoria. Revista de Empreendedorismo e Gestão de Pequenas Empresas, v. 3, n. 2, p. 94-119, 2014. 